\title{
Research on Application Status and Countermeasures of Modern Educational Technology in College Physical Education
}

\author{
Yang Zhang \\ Dept. of P.E. Education, Xi'an University of Science and Technology, Xi'an 710054, China
}

zhangyang@163.com

Keywords: Modern Educational Technology, Physical Education

\begin{abstract}
The 21st century is a new century when human beings have the fully access to the information society. With the development and wide application of the modern educational technology, education is going to take on the modernization features and the trends of development. In this paper, there is discusses and researches on important questions of modern information technology application in university sports teaching; then this thesis puts forward preliminary idea and prospect about modern information technology application in university sports teaching in the future. This thesis draws the conclusion and offers some feasible suggestion on the modern information technology application in the university sports teaching. After consideration of physical education in college and physical education in information technology, the modern educational technology used in sports teaching has become the most important topic. The application of the modern educational will have a profound and positive effect on the physical education.
\end{abstract}

\section{Theoretical Introduction of Modern Educational Technology}

Combined comprehensive international research results and Chinese reality, the modern educational technology is defined as: modern educational technology refers to the use of modern educational theory and modern information technology. Which include the organic integrated media facilities of modern education technology, educational psychology techniques, education, information and communication technology. The modern educational technology can solve problems involving various levels of education, including educational planning, curriculum development, educational structures and evaluation.

The basic idea of modern educational technology analysis and problem-solving is learner-centered. Modern educational technology is concerned that the needs of learners, teachers led to indirect forms of teaching, by design, hosting, demonstration and assessment to teacher-led teaching duties. Modern educational technology research and practice is the object of the learning process, the students established a dominant position in the learning process. Modern educational technology resources, emphasis on learning design, development, utilization and management, not only research teaching resources, but also attach importance to the study of the teaching process, as long as contact occurs with learning resources, learners can use their own deems appropriate way to learn. Modern educational technology learning resources using a systems approach to a variety of teaching methods and learning process needed for design, development, utilization, management and evaluation ${ }^{[1]}$.

In the information age, in promoting quality education today, with the diversification of information, large-scale, information exchange complex, ever-changing knowledge, students received education more colorful, more complex interaction between teachers and students, with the development of science and technology teaching methods will inevitably have changed a lot, any university can't ignore the existence of modern educational technology. And other modern educational technology impacts on the education system systematically all the elements of the whole process of design and operation, which is designed to achieve optimal configuration elements and functions, and play the best features of the education system to achieve optimal education. 


\section{Application Advantages of Modern Educational Technology}

Sports education process has become the process of developing and enhancing students' subjectivity, consciousness and body training with the ability to learn the subject of comprehensive development. Physical education modern educational technology can not only help students complete the physical good skills sportsmanship and attitude objectives, but also achieve the goal of developing students' subjectivity. Physical education students pay more attention to the skills, education and more emphasis on visualization, according to the status and characteristics of physical education in the modern educational technology in physical education to better reflect its sporting characteristics and application value. Application advantages of modern educational technology in college sports education are as follows ${ }^{[2]}$. Fig.1 shows the application advantages of modern educational technology.

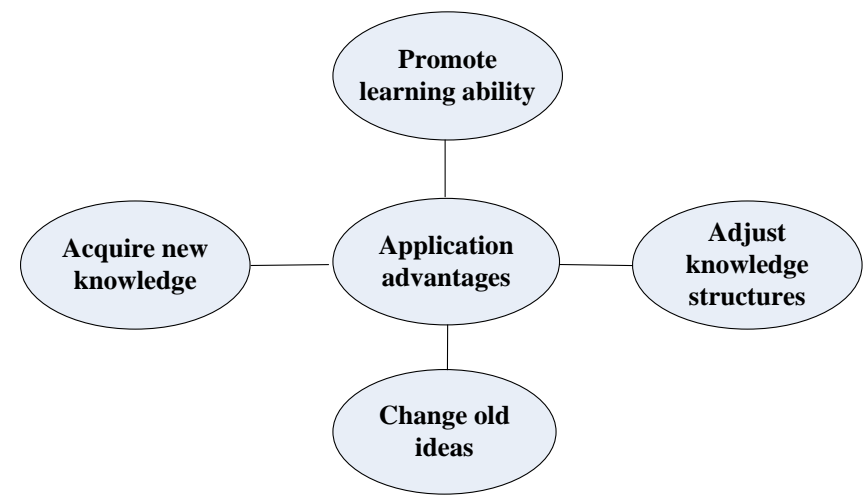

Fig. 1.The application advantages of modern educational technology

Modern educational technology can help acquire new knowledge. One of the purposes of teaching reform is to enable students to absorb more new ideas, learn the skills and updated knowledge, acquire more new methods related to the professional and professional. There is no doubt that our current classroom less information and less integrated degree courses must be thorough reform from the nature, structure, form and methods. Tradition teach is centered teaching environment oriented teachers teach, educate students become the object of knowledge, knowledge acquisition is passive; while learning-centered learning is oriented students are the subject of cognition. Modern educational technology is the most effective technology for the learning space. Students can select the knowledge in line with the interest in learning to deepen the integration of knowledge of modern educational technology can improve the education of students' innovative spirit and the concept of capacity development

Modern educational technology can help adjust the students' knowledge structures .Currently, the physical education has curriculum adjustments to varying degrees during the purpose is to adjust the student's knowledge structure to adapt to the needs of the arrival of the information age. In addition to the need to strengthen physical education, should also greatly enhance the humanities, social sciences, computer, English and other aspects of education, which inevitably makes the students the basics of traditional structure has undergone great changes. Physical education can provide teaching situations for students to visualize in the use of modern educational technology, and play on human visual function dual stimulation to stimulate the students with great curiosity and thirst for knowledge to observe attentively and thinking. In the novel stimulus animation, easy-to-active students' thinking ability and imagination, and thus stimulate innovation. Modern information technology to promote the expansion of classrooms, students can promote sports competition ability. It can’t be time constraints, extended classroom ${ }^{[3]}$.

\section{Situation Analysis of Modern Educational Technology}

The uses of modern educational technology give full play to the advantages of the theory in-depth teaching, resources and the environment, the application of modern educational technology in 
physical education makes sports teaching the elements in a positive good interaction state. Intellectual and non-intellectual factors make factors have been developed to improve the quality of teaching sports and ultimately enable students to achieve the educational purpose of comprehensive development. Interactive use of modern educational technology to implement innovative teaching mode, teaching classes and controls were compared and analyzed using qualitative and quantitative analysis described methods provide theoretical and practical basis for optimizing physical education quality ${ }^{[4]}$.

By carrying out teaching experiments, the use of modern educational technology implemented in the experimental class Physical Education. According to the teaching goals, through the use of modern educational technology and teaching strategies to implement the sequence of operations carried physical education, and the corresponding teaching evaluation study its application results. Interactive observational study physical education, and then to be the result of comparison of two classes, to explore whether the implementation of modern educational technology to improve student interaction plays participation in physical education, and promote the development of students' motivation to learn the role. Sports test analysis. That sports testing end of the experiment to verify the implementation of modern educational technology on student achievement and Sports Physical interest in learning, attitudes impact

Most physical education teachers have a considerable degree of master of computer-assisted teaching tools and means of sports students' perceptions of the teaching of modern educational technology, a clear understanding of the significance of modern educational technology in physical education applications. Teachers of the school of modern multimedia classroom equipment status quo satisfaction survey shows 72.65 percent of the teachers in the current status of multimedia classroom equipment than satisfied or very satisfied, 23 were accounted for $19.66 \%$ of teachers think that in general, only $7.69 \%$ of teachers say not very satisfied or not satisfied. From the results of the survey, the current status of the various schools of modern multimedia classroom equipment satisfaction or higher. Fig.2 shows the teacher satisfaction with modern equipment multimedia classrooms.

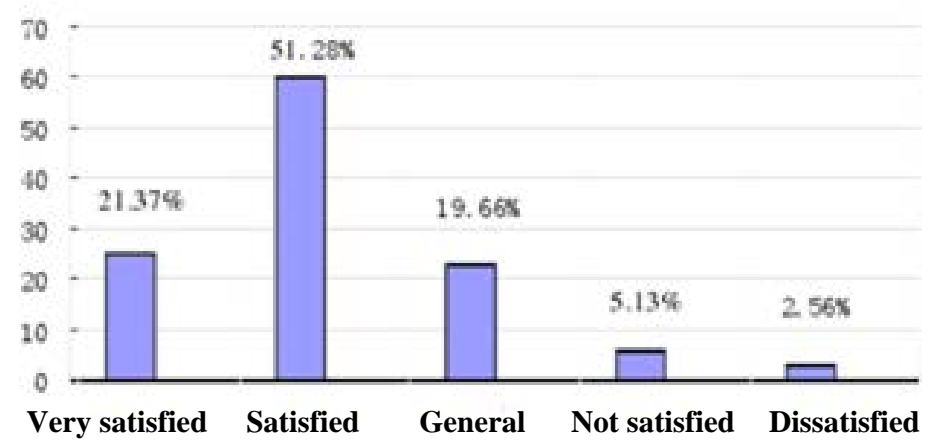

Fig. 2 The teacher satisfaction with modern equipment multimedia classrooms

\section{Strengthen Management Measures and Suggestions}

The application of modern educational technology becomes more widely, which will inevitably cause problems in the actual teaching, if not solve these problems, physical education teaching quality will be affected. The only way to ensure modern educational technology is widely used in college sports teaching. Physical education Information management is a major component of physical education management. Universities should take the necessary measures to establish a special department of modern educational technology as soon as possible, and design appropriate characteristics of physical education physical education management information system to save human resources and improve the level of sports information to achieve resource sharing, the implementation of scientific sports management also has great significance ${ }^{[5]}$.

The modern educational technology is rational use, and promoting physical education for college ,which is helpful to improve the efficiency of learning, teaching in favor of modern 
management, help reduce the workload of physical education teachers, conducive to the use of network resources, educational resource sharing. Change the concept of physical education teachers and teaching physical education teachers to broaden their knowledge, training requirements of computer-aided teaching, which is a combination of modern technology and traditional sports education teaching methods. The use of modern educational technology can greatly improve the efficiency of physical education, and reduce the workload of physical education teachers.

With the popularization and application of network technology and multimedia technology, and campus network environment of modern educational technology university has been greatly improved, good teaching environment of modern educational technology can promote better physical education teachers in teaching the application of modern educational technology. Therefore, we must take the necessary measures to effectively solve the longer the construction of the modern educational technology environment. Colleges and universities in order to achieve a modern educational technology into teaching in the development of hardware facilities is based on the configuration of PE teaching reflects the level of modernization level of college physical education . Physical Education in the implementation of modern educational technology software environment is also important.

\section{Conclusions}

Because the unceasing development and the widespread application of the information technology, the education will present the characteristic and the development trend of modernization. In this paper, we have research on the current situation of some physical education application of modern education technology in teaching. It also analyzes the bottleneck of restriction, and puts forward relevant suggestions for the purpose of deriving further perfect methods of promoting the modern education technology in college physical education in the application service. This study explores the way of application of modern educational technology to college physical teaching under the direction of the modern educational thoughts and method. The corresponding measures and suggestions are put forward through the survey and analysis, as the reference for the development of college physical education teaching. And application of modern educational technology has a wide development in other courses, making great achievements.

\section{References}

[1] S. D. D. V. Rughooputh, M. I. Santally. Integrating text-to-speech software into pedagogically sound teaching and learning scenarios [J].Educational Technology Research and Development.2007, 57( I):13I-145.

[2] Jared Keengwe ,Grace Onchwari, Patrick Wachira. Computer Technology Integration and Student Learning: Barriers and Promise[J].Journal of Science Education and Technology,2008,17(6): 560-565.

[3] Hanadi Kassem Saleh. Computer self-efficacy of university faculty in Lebanon[J].Educational Technology Research and Development.2008,56(2):229-240.

[4] Jing Lei Blame Morrow. Teachers' adoption of technology innovation into pedagogical practices [J].Education and Information Technologies, 2010, 15(3): 143-153.

[5] David A. Cook, Anthony J . Levinson, (3) Sarah Garside. Time and learning efficiency in Internet based learning: a systematic review and meta-analysis [J].Springer Netherlands, 2010, 15(5): 755-770. 